Historic, archived document

Do not assume content reflects current scientific knowledge, policies, or practices 



\section{Processing Seed of Grasses and Other Plants To Remove Awns and Appendages}

By John L. Schwendiman and Roland F. Sackman, assistant agronomists, and A. L. Hafenrichter, senior agronomist, Nursery Division, Soil Conservation Service

\section{CONTENTS}

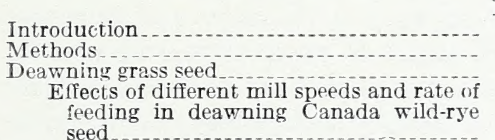

Page Deawning grass seed-Continued.

Data on seven grasscs deawned at opti- Page mum operation of mill

4 Deawning other seeds

Relation of optimum mill speed to diameter of cylinder seed.

4 Summary .

\section{INTRODUCTION ${ }^{1}$}

The difficulty of using the ordinary machinery in planting seed with appendages that are not removed in the normal threshing operation has retarded the use of several valuable plants in general agriculture and in nursery plantings. It is frequently possible to eliminate these undesirable appendages by breeding, but this method of improvement may require several years. At the Pullman nursery, Pullman, Wash., the removal of appendages by mechanical means has been demonstrated to be commercially feasible and has been accomplished with a minimum of injury to the seed in processing ${ }^{2}$ seed of several of the native and introduced plants adapted to the Pacific Northwest.

This processing has facilitated the use of these grasses, valuable for erosion control and moisture conservation, making it possible to plant them with grain drills. Over 8,000 pounds of processed seeds were used on farms, demonstration projects, and work areas of the Soil Conservation Service in the Pacific Northwest in the spring of 1939, including 5,600 pounds of tall oatgrass, 900 pounds of Canada wild-rye, and 850 pounds of blue wild-rye. Although some small lots were

${ }_{1}$ The methods reported in this circular were developed at the Pullman unit of the Nursery Division, Soil Conservation Service, to facilitate the regular nursery work, which is done in cooperation with the Washington Agricultural Experiment Station and the Bureau of Plant Industry, U. S. Department of Agricuiture.

2 The term "process" as used in this circular includes both milling and c'eaning. 
seeded alone, most of the seed was sown as part of a grass mixture planted to alfalfa or as part of a sweetclover-grass mixture. Reports from field agronomists and farmers who have previously handled unprocessed seed agree that in addition to facilitating planting, processing promotes more uniform stands and reduces the labor required to make the seedings.

\section{METHODS}

Seed of bluebunch wheatgrass (Agropyron spicatum), blue wild-rye (Elymus glaucus), Canada wild-rye (E. canadensis), Siberian wild-rye (E. sibericus), tall oatgrass (Arrhenatherum elatius), bulbous barley (Hordeum bulbosum), squirreltail (Sitanion hystrix), alfileria (Erodium cicutarium), and virgins-bower (Clematis ligusticifolia) was used in the studies at the Pullman nursery. The seed of bluebunch wheatgrass, blue and Siberian wild-rye, tall oatgrass, and squirreltail were machine threshed; the other seed had been threshed by hand. Attempts to remove the awns from grass seed, the tails of the carpels from alfileria, and the styles from virgins-bower by rubbing, burning with a torch, or using small bur mills, were slow and expensive and damaged a high percentage of the seed. One lot of Canada wild-rye was successfully deawned at the nursery in the normal threshing operation by speeding up the cylinder, using three rows of concave teeth set to thresh close, adjusting the sieves, and removing twothirds of the fan blades to reduce the air blast. However, the grass was harvested with a binder at an early stage of maturity and was so cured in the shock as to obtain a desirable moisture content at the time of threshing. Under conditions of large-scale operations attention to such factors is hardly practical. One commercial seed grower in the Northwest had used the hammer mill to break up the multiple florets common in threshed seed of crested wheatgrass (Agropyron cristatum). These experiences suggested the use of the mill for deawning seed. ${ }^{3}$

Two types of medium-sized hammer mill were used. Most of the work was done with the swinging-hammer type, and for comparison a solid-hammer type was used in deawning two typical species. The detailed specifications for each mill are given in table 1 . These mills represent the types and sizes most commonly used on farms in the Pacific Northwest. Other mills were available but were not equipped with screens suitable for use in these studies.

TABLE 1.-Specifications for two typical medium-sized hammer mills used for deawning grass seed

\begin{tabular}{|c|c|c|c|c|c|c|}
\hline Type of hammer & $\begin{array}{l}\text { Feed open- } \\
\text { ing }\end{array}$ & $\begin{array}{l}\text { Size of } \\
\text { screen }\end{array}$ & $\begin{array}{l}\text { Diameter } \\
\text { of cylincler }\end{array}$ & Hammers & $\begin{array}{l}\text { Hammer } \\
\text { tips }\end{array}$ & $\begin{array}{l}\text { Normal } \\
\text { grinding } \\
\text { speed }\end{array}$ \\
\hline $\begin{array}{l}\text { Swinging - } \\
\text { Solid_-_- }\end{array}$ & $\begin{array}{l}\text { Inches } \\
9 \text { by } 131 / 2 \\
11 \text { by } 14\end{array}$ & $\begin{array}{l}\text { Inches } \\
113 \text { by } 44 \\
14 \text { by } 36\end{array}$ & $\begin{array}{r}\text { Inches } \\
26 \\
22\end{array}$ & $\begin{array}{r}\text { Number } \\
24 \\
30\end{array}$ & $\begin{array}{r}\text { Number } \\
48 \\
30\end{array}$ & $\begin{array}{r}\text { Revolutions } \\
\text { per minute } \\
2,250 \\
2,250\end{array}$ \\
\hline
\end{tabular}

1 An additional 1/2-inch screen 13 by 28 inches is spot-welded in the hood of this machine.

3 This method has also been reported in the following: WEBER, G. L. A METHOD OF PREPARING SOME NATIVE GRASS SEEDS FOR HANDLiNg ANd SEeding. Amer. Soc. Agron. Jour. 31:729-733. 1939. 
Preliminary trials with the hammer mill indicated that deawning of Canada wild-rye was only partly accomplished and that damage to the seed was high. Tests were then made to determine the effect of cylinder speed, rate of feeding, screen size, and number of times milled on deawning and damage to the seeds. It was apparent that proper adjustments of these four factors could be made to obtain a high percentage of awn removal, little or no damage, and a product that could easily be seeded with ordinary farm machinery. The detailed data presented in table 2 for Canada wild-rye show the relation of speed of cylinder and rate of milling to the other factors in this table. Tests similar in detail were made with the other species studied but only averages for the optimum operation of the mill are given (table 3 ).

Each lot of grass seed used in these studies was carefully examined before being processed to determine gross weight, test weight per bushel, number of seeds per pound, percentage deawned, percentage injured, percentage of purity, and percentage of germination. Test weight per bushel was determined from 3 aliquot samples by the use of a Boerner sampler in the usual manner. This may not be entirely accurate for grass seed, but since the same procedure was used throughout the studies, the tests of all the grasses are comparable. The number of seeds per pound was determined by averaging the number of seeds in 4 aliquot samples. The samples of the several species ranged from 2 to 8 grams. The percentage of seed deawned was determined by separating lots of 100 seeds, each taken from 3 aliquot samples, into awned and deawned fractions. Three lots of 100 seeds each were examined under the microscope, with a magnification of 10 to 20 diameters, to ascertain injury caused by threshing. Purity and germination tests were made according to standard procedure in seed laboratories; the percentage of purity was obtained from 1 aliquot sample of standard size and germination from 4 samples of 100 seeds each. The expression of purity and germination in one figure in terms of percentage of live pure seed was adopted because this criterion is commonly used in trade channels and hence has the advantage of practicability.

After the seed was milled to remove the awns from grass and the appendages from alfileria and virgins-bower, it was cleaned with a Clipper cleaner, model 16 , to remove inert matter consisting chiefly of awns, straw, chaff, and cracked and ground seed. The tests made on the original seed were then made on the processed seed. By comparing the two sets of tests the effect of the methods used in milling can be determined.

Accurate data on cost were recorded for all the trials. Labor was charged at 50 cents an hour, use of the mill and power at 23 cents, and use of the cleaner and power at 8 cents. These figures represent direct charges made at the nursery and are based on data accumulated for cost accounting. Milling and cleaning were computed separately. To each operation was added a charge of 30 percent for supervision and normal overhead. The total cost of both operations is presented as the cost of processing (table 3). 


\section{DEAWNING GRASS SEED}

\section{Effect of Different Mill Speeds and Rate of Feeding in Deawning Canada Wild-Rye Seed}

The preliminary deawning trials were made with seed of Canada wild-rye. This seed has long, stiff, curved awns, which make it bulky; consequently the test weight is low, 5 to 7 pounds per bushel. The tendency of this grass to ball when handled makes planting it with ordinary machinery almost impossible. A typical sample is shown in figure 1, $A$. In the lot chosen 93.5 percent of the seed was awned and hence was well suited for the deawning tests. The swinginghammer mill, detailed specifications for which are given in table 1, was used. It was driven by a gasoline power unit, the speed of which could be regulated by means of a throttle. Seed was fed into the mill by hand.

The initial trial, made at 2,250 revolutions per minute (r. p. m.), the normal grinding speed of the mill, with a 1/4-inch screen, gave ground seed. The screen was removed in the next trial. Without the screen, 50 percent of the seed was ground, and the remainder was not deawned. The use of a $3 / 4$-inch screen increased the amount of ground seed to 75 percent; the remaining 25 percent retained the awns. Provision was made to reduce the speed of the mill by installing a jack shaft between it and the motor. The pulleys used were capable of reducing the speed approximately one-half, so that with throttle control on the motor the mill could be operated accurately and smoothly at any desired speed between 480 and 1,120 r. p. m. It was found that a mill speed of about $700 \mathrm{r}$. p. m. with a 1/4-inch screen gave a high percentage of deawned seed and a low percentage of injured seed. It was also observed that the rate of feeding affected the quality of the seed.

After the preliminary trials, tests were begun to measure the effect of mill speed and rate of feeding on deawning. For each test a minimum of 30 pounds of seed and 3 minutes of operation were found necessary to obtain reliable data. The speeds of the hammer-mill cylinder were set and maintained with a Starret speed indicator. Two rates of feeding were used; the full rate, being that required to operate the mill at capacity without reducing the speed, and the half rate, at approximately half the capacity. Each trial was made in triplicate, care being taken to collect treated seed from the mill only while it was in full, continuous operation. This procedure assured representative samples and reduced error. The milled seed was cleaned, and aliquot samples were taken to measure the effect of the method of operation on the criteria shown in table 2. The data for three speeds of operation and the two rates of feeding are given in this table. Only averages of the three trials are given because of the slight variation obtained when one lot of seed was used throughout and the same operator fed the mill.

A mill speed of 600 r. p. m. deawned 96 percent of the seeds and injured only 1.12 percent of the caryopses when the seed was fed at the capacity of the machine. Operating the mill at higher speeds increased the percentage of injured seed but had little effect on the percentage of seed deawned. Feeding the mill at approximately one- 
half capacity reduced the deawning and materially increased the amount of injured seed. The exact amount of seed lost by grinding, under the conditions of the tests, could not be determined, but examination of the cleanings indicated that a very small percentage was ground when the mill was operated at 600 r. p. m. The material removed by cleaning consisted chiefly of awns, portions of the hull, and other inert matter. The amount of ground seed increased at speeds above 600 r. p. m., especially when the mill was fed at half capacity.

TABLE 2.-The effect of cylinder speed and rate of feeding during milling on processed seed of Canada wild-rye (Elymus canadensis)

[The data are averages of three trials in each of which 30 pounds of seed was used.]

\begin{tabular}{|c|c|c|c|c|c|c|c|c|c|c|}
\hline $\begin{array}{l}\text { Speed of } \\
\text { cylinder } \\
\text { (r.p.m.) }\end{array}$ & \multicolumn{2}{|c|}{ Rate of milling } & $\begin{array}{c}\text { De- } \\
\text { awned }\end{array}$ & Injured & $\begin{array}{l}\text { Loss in } \\
\text { weight }\end{array}$ & Purity & $\begin{array}{l}\text { Germi- } \\
\text { nation }\end{array}$ & $\begin{array}{l}\text { Live } \\
\text { pure } \\
\text { seed }\end{array}$ & $\begin{array}{l}\text { Seeds } \\
\text { per } \\
\text { pound }\end{array}$ & $\begin{array}{c}\text { Test } \\
\text { weight } \\
\text { per } \\
\text { bushel }\end{array}$ \\
\hline $\begin{array}{l}\text { Check. } \\
600 \\
720 \\
830\end{array}$ & $\begin{array}{l}\left\{\begin{array}{l}\text { Half } \\
\text { Full }\end{array}\right. \\
\left\{\begin{array}{l}\text { Half } \\
\text { Full }\end{array}\right. \\
\left\{\begin{array}{l}\text { Half } \\
\text { Full }\end{array}\right.\end{array}$ & $\begin{array}{r}\text { Pounds } \\
250 \\
600 \\
300 \\
700 \\
350 \\
800\end{array}$ & $\begin{array}{r}\text { Percent } \\
6.5 \\
79.0 \\
96.0 \\
83.5 \\
96.5 \\
86.5 \\
96.5\end{array}$ & $\begin{array}{r}\text { Percent } \\
0 \\
3.37 \\
1.12 \\
11.87 \\
5.25 \\
24.87 \\
9.87\end{array}$ & $\begin{array}{r}\text { Percent } \\
22.0 \\
28.0 \\
36.0 \\
32.0 \\
45.0 \\
34.0\end{array}$ & $\begin{array}{r}\text { Percent } \\
93.5 \\
98.1 \\
96.8 \\
97.3 \\
98.2 \\
97.4 \\
98.4\end{array}$ & $\begin{array}{r}\text { Percent } \\
97.75 \\
98.00 \\
98.75 \\
89.00 \\
95.50 \\
73.30 \\
90.55\end{array}$ & $\begin{array}{r}\text { Percent } \\
91.40 \\
96.14 \\
95.59 \\
86.63 \\
93.78 \\
71.39 \\
89.10\end{array}$ & $\begin{array}{c}\begin{array}{c}\text { Thou- } \\
\text { sands } \\
67.6\end{array} \\
79.9\end{array}$ & \begin{tabular}{r} 
Pounds \\
5.8 \\
29.5 \\
\\
\hdashline \\
\end{tabular} \\
\hline
\end{tabular}

Processed seed is easily planted with ordinary machinery, whereas untreated seed is very difficult to plant. This is reflected in table 2 , which shows that processing increased the number of seeds per pound from 67,600 to 79,900 , or 18.2 percent. This increase is great, but it is to be expected because the large awns in the untreated sample make up a considerable part of the weight.

Table 2 also gives the results of tests to determine the changes in quality of Canada wild-rye seed associated with changes in the method of milling. The data show that processing improves the purity only about 4 percent, which is not a significant difference. This is to be expected because this seed is easy to clean and the percentage of purity of the original lot was high. Germination tests indicated that the treatment affected viability, reducing it measurably when cylinder speeds above the optimum for the species were used and still further with low rates of feeding. The germination of seeds processed at $600 \mathrm{r}$. p. m. was slightly improved, but the difference is not regarded as significant. There is an inverse relationship between percentage of injury and germination, germination decreasing as the percentage of injured seed increases. "Live pure seed," which integrates purity and germination, also shows this same relationship.

The data also indicate that the loss in weight due to milling at optimum speed and rate is largely offset by increased quality as measured by live pure seed and the number of seeds per pound. The total loss in weight at 600 r. p. m. and full rate of feeding was 28.0 percent, but live pure seed increased 4.19 percent and seeds per pound 18.2 percent. Another improvement is the reduction in the volume of the processed seed to nearly one-fifth that of the original sample, as indicated by the reciprocal of the increase factor for change 


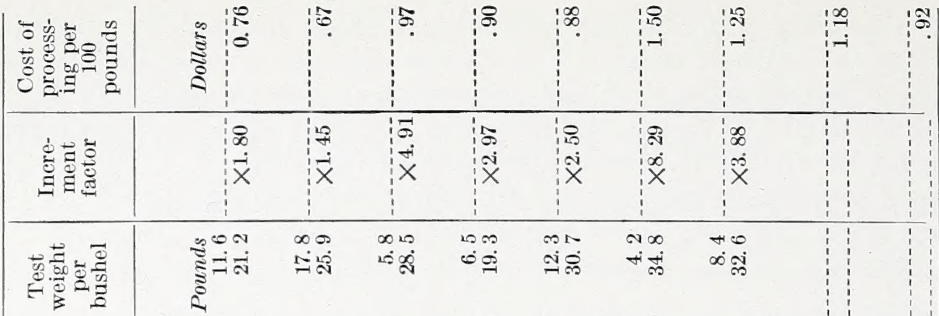

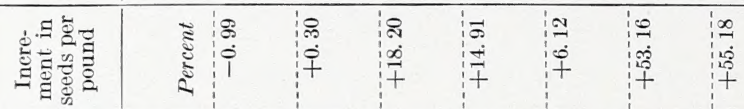

\begin{tabular}{|c|c|c|c|c|c|c|}
\hline 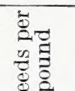 & ذُ & 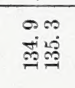 & $\begin{array}{l}00 \\
0.8\end{array}$ & $\begin{array}{l}n 0 \\
\dot{g} \\
\dot{\sigma}\end{array}$ & स्य & $\overrightarrow{\mathrm{m}}$ \\
\hline
\end{tabular}

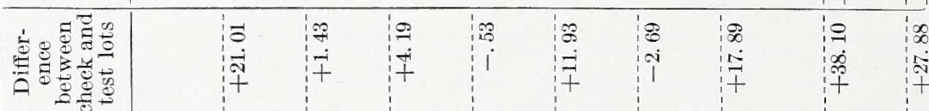

\begin{tabular}{|c|c|c|c|c|c|c|c|c|}
\hline 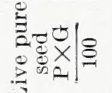 & 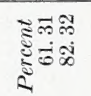 & 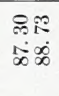 & $\begin{array}{l}\text { 왐 } \\
\text { के } 18\end{array}$ & $\begin{array}{l}\mathscr{8} \\
: \\
8\end{array}$ & 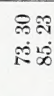 & $\begin{array}{l}\infty \\
\infty \\
N \\
N\end{array}$ & $\begin{array}{l}0.0 \\
0 \\
0 \\
0\end{array}$ & $\begin{array}{l}\text { ชิ พ } \\
\text { ธี่ }\end{array}$ \\
\hline
\end{tabular}
9

\begin{tabular}{|c|c|c|c|c|c|c|c|c|c|}
\hline 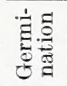 & 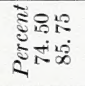 & $\begin{array}{l}88 \\
\infty \\
\infty \\
\infty \\
\infty\end{array}$ & 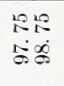 & 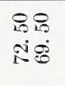 & $\begin{array}{l}88 \\
\infty 8 \\
\infty\end{array}$ & 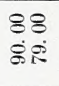 & 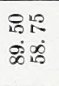 & 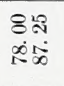 & 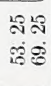 \\
\hline$\vec{\Xi}$ & 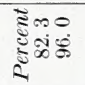 & $\begin{array}{l}\text { NN } \\
\qquad \dot{S}\end{array}$ & $\begin{array}{l}10 \infty \\
\wp \& \\
\wp \&\end{array}$ & $\begin{array}{l}10 \% \\
\dot{\delta} \dot{\rho}\end{array}$ & $\begin{array}{l}m 1 \\
\infty 5 \dot{0}\end{array}$ & $\begin{array}{l}\sim \infty \\
\dot{\infty} \\
\dot{\infty}\end{array}$ & $\begin{array}{l}0.0 \\
F \\
F\end{array}$ & $\begin{array}{l}\ddot{0} \\
+\infty\end{array}$ & $\begin{array}{l}\infty+1 \\
\dot{0}+\infty\end{array}$ \\
\hline
\end{tabular}

\begin{tabular}{|c|c|c|c|c|c|c|c|c|c|c|c|}
\hline 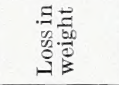 & $\begin{array}{l}\widetilde{E} \\
\mathbb{E} \\
\mathbb{E}\end{array}$ & & $\infty$ & ${ }^{\circ}$ & $\begin{array}{l}\stackrel{0}{\infty} \\
\infty\end{array}$ & ป & : & $\begin{array}{l}0 \\
6\end{array}$ & i. & $\begin{array}{l}8 \\
\dot{3}\end{array}$ & $\begin{array}{l}\infty \\
: 8\end{array}$ \\
\hline 鸹 & 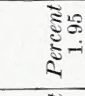 & & 88 & & $\stackrel{7}{9}$ & 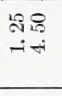 & $\begin{array}{l}\text { â? } \\
\text { tio }\end{array}$ & 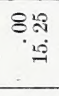 & $\begin{array}{l}108 \\
\text { ․ㅛ }\end{array}$ & 8.10 & $\begin{array}{r}810 \\
6 \\
6\end{array}$ \\
\hline 它总 & 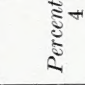 & & $\infty$ & & 08 & ినః & $\infty \varnothing$ & $\infty \cong$ & Nळ & 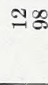 & N\&) \\
\hline 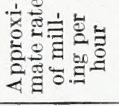 & 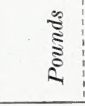 & : & & 8 & छ్ & § & 8 & స్ & ః्. & F & i: \\
\hline 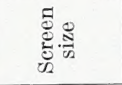 & $\Xi$ & $I^{-}$ & & H & - & $\mathbb{3}$ & $\stackrel{0}{\circ}$ & $\mathbb{E}^{\prime \prime}$ & IH & & \\
\hline 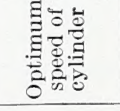 & 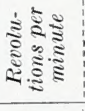 & :ึิ & & 8 & 8 & 保 & เิ & 居 & § & 8 & : \\
\hline 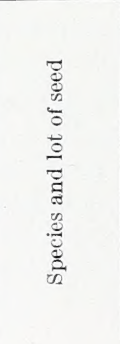 & 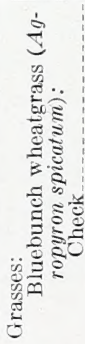 & 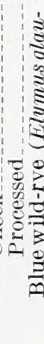 & $\begin{array}{r} \\
\\
\\
0 \\
0\end{array}$ & 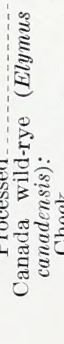 & 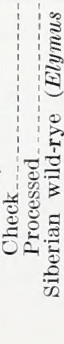 & $\begin{array}{l}5 \\
5 \\
-5 \\
0 \\
0\end{array}$ & $\begin{array}{c}0 \\
0 \\
0 \\
0 \\
0\end{array}$ & $\begin{array}{r} \\
\\
\\
0 \\
0 \\
0 \\
0 \\
0 \\
0\end{array}$ & 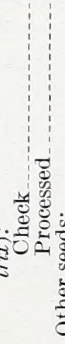 & $\begin{array}{l}0 \\
\\
\end{array}$ & 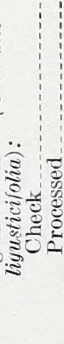 \\
\hline
\end{tabular}


in test weight per bushel $\left(\frac{28.5}{5.8}=4.91\right)$. This decrease in volume

materially facilitates storage and handling. The cost of processing averaged 97 cents per 100 pounds at 600 r. p. m. and full rate of feeding. When all the data are carefully considered, it is evident that seed of Canada wild-rye can be successfully deawned at low cost if the speed, rate of feeding, and size of screen used in the mill are determined. The improvement made by processing this seed can be seen by comparing the unprocessed and deawned seeds in figure 1 . It is clearly evident that processing greatly facilitates handling.

\section{Data on Seven Grasses Deawned at Optimum Operation of Mill}

Following the procedure used in deawning Canada wild-rye, trials were conducted with seed of six other awned grasses. The replicated determinations of proper mill speed, rate of feeding, size of screen, and tests subsequent to processing are not presented. Table 3 gives for the several grasses the averages of the three trials in which the mill was operated at optimum speed.

\section{MILL SPEED AND SIZE OF SCREEN}

Milling to remove the awns from grass seed was successfully accomplished with all species (figs. 1-6) when the correct speed of cylinder and size of screen were determined. Only one rate of feeding, that required to operate the mill at capacity, was used with all species for which data are presented. The limits for mill speed with grass seed of different species range between 590 and 800 r. p. m. and can be determined within 50 r. p. m. The desired final degree of awn removal can be obtained by attention to mill speed irrespective of the percentage of seed deawned by threshing before processing. The percentage deawned before processing was found to have no effect on the method of milling but influenced the rate at which milling could be done.

The percentage of seed deawned after the processing fell below 93 percent for only tall oatgrass. When the mill was operated between 600 and 800 r. p. m. the percentage of tall oatgrass seed deawned was too low to be satisfactory, and at higher speeds the amount of injured seed was too great. A mill speed of 720 r. p. m. gave 20 percent of deawned seed and 35 percent hulled, with less than 1 percent injured. This product failed to flow through a drill satisfactorily. Consequently the awned fraction was scalped off and milled a second time. Both fractions were then combined, cleaned, and tested. After this second milling, 86 percent of the seed was deawned; 36 percent was intact, and 50 percent was hulled. Less than 3 percent was injured in processing. As the data in table 3 show, the quality of the seed was improved. (See fig. 2.)

It was also necessary to process bulbous barley twice in order to obtain the desired degree of awn removal and hold injury to a minimum. After this seed was milled once, about 30 percent was still awned. This fraction was recovered by running the product from the 


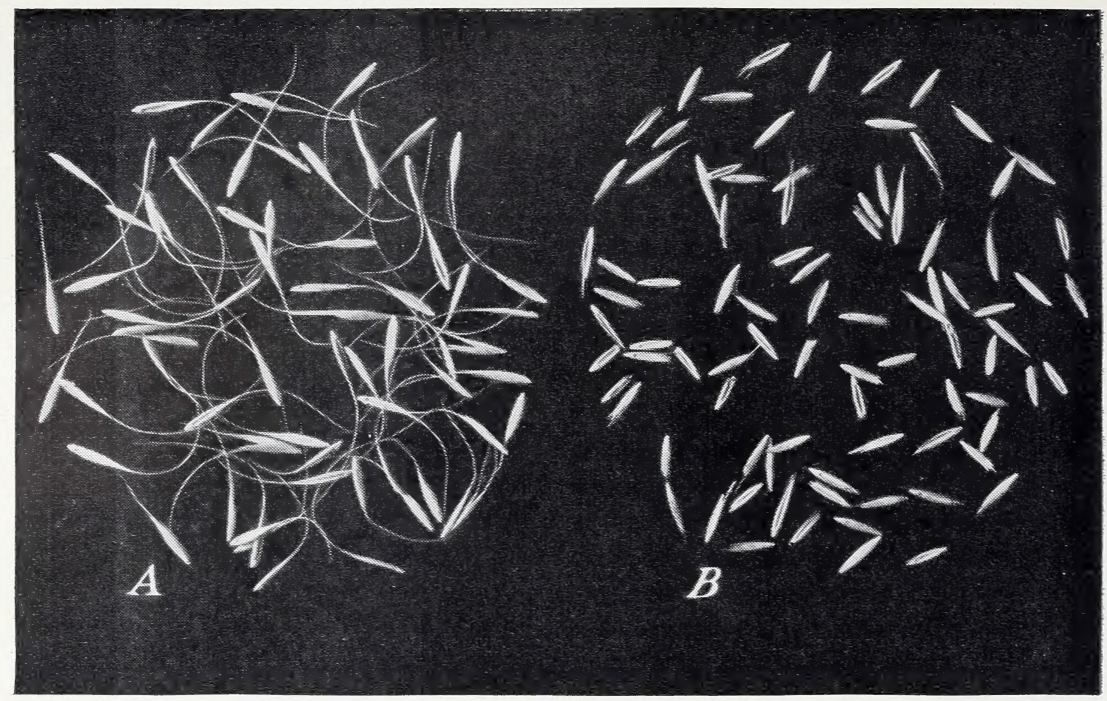

Figure 1.- Seed of Canada wild-rye (Elymus canadensis) before $(A)$ and after $(B)$ it was processed. The awns are stiff, long, and curved and make up a considerable proportion of the weight of the seed.

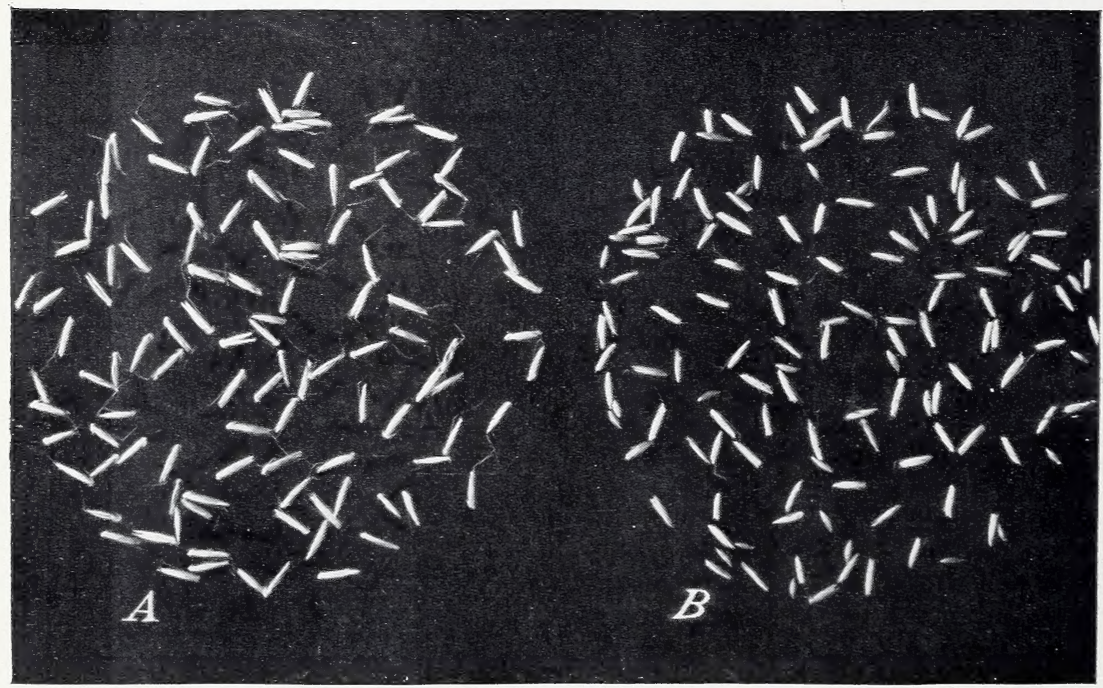

FIGURE 2.- Seed of a commercial lot of tall oatgrass (Arrhenatherum elatius) before $(A)$ and after $(B)$ it was processed to remove the awns. About 85 percent of the seed in $B$ is deawned and a considerable portion is hulled, but it can be easily planted with ordinary machinery and is of superior quality. 

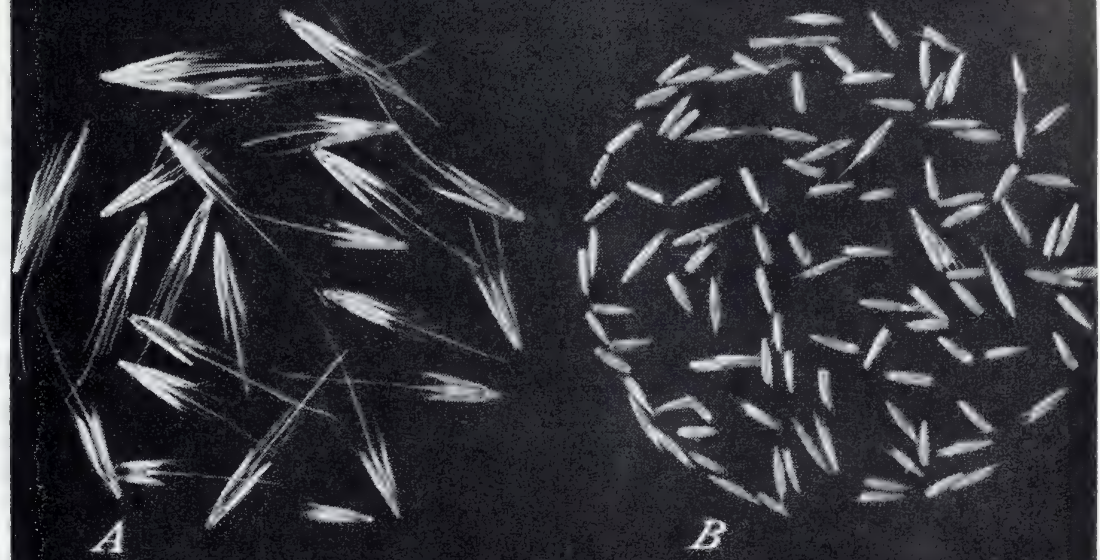

FIGURE 3.-Typical spikelets of bulbous barley (Hordeum bulbosum) are shown in $A$ and processed seed in $B$. This seed is difficult to mill without some injury, but it is almost impossible to plant unprocessed seed.

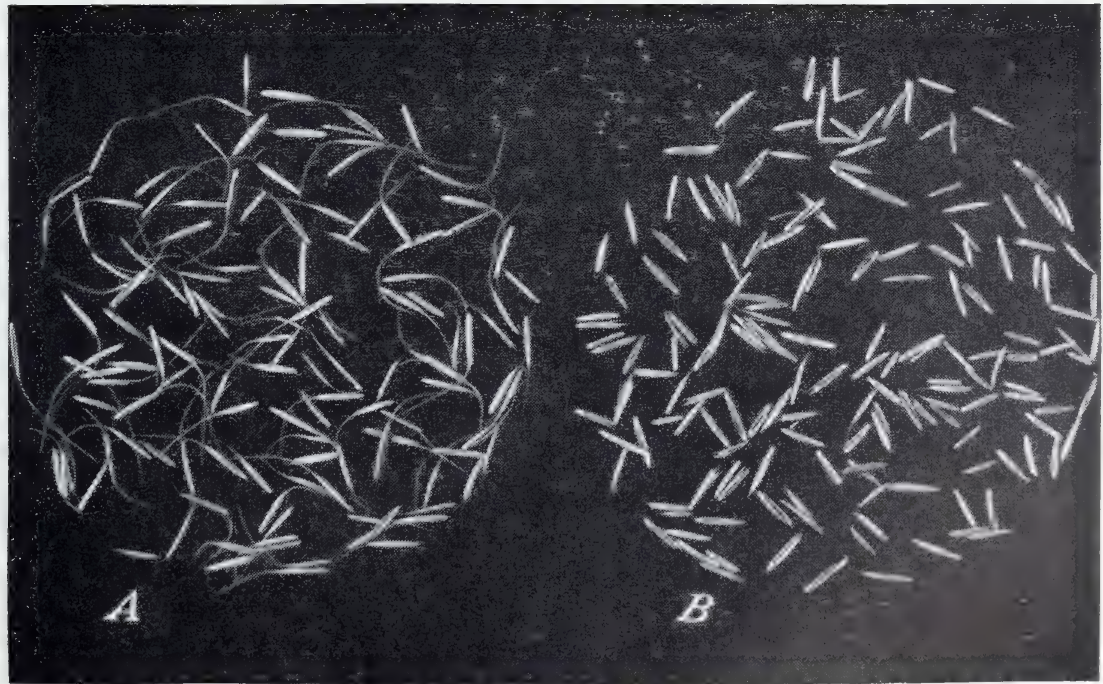

Figure 4.-Seed of bluebunch wheatgrass (Agropyron spicatum) before $(A)$ and after $(B)$ it was processed. 


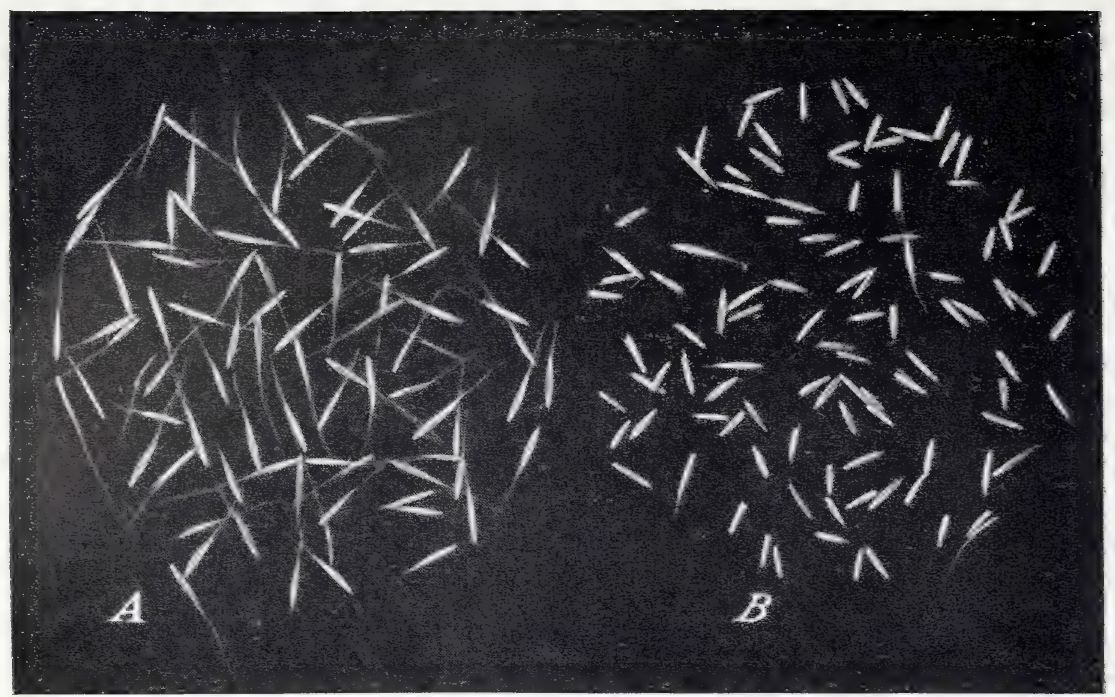

Figure 5.-Seed of blue wild-rve (Elymus glaucus) before $(A)$ and after $(B)$ it was processed. The short, slender awns of this seed are easily removed by milling.

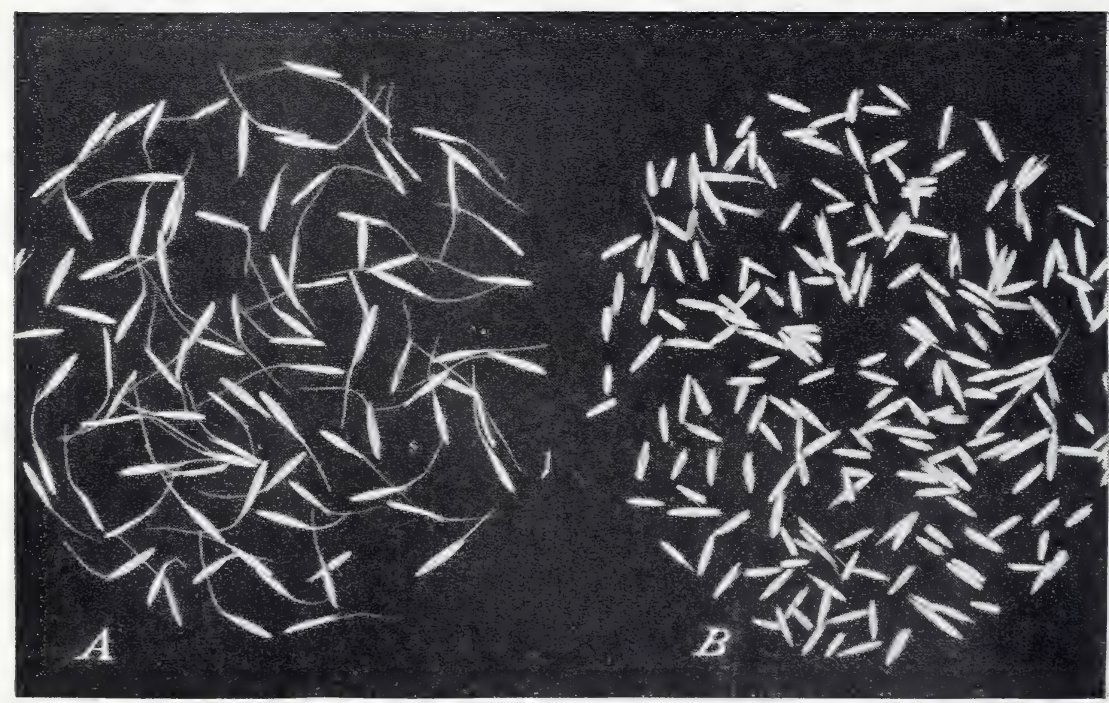

Figure 6.-The effect of processing seed of Siberian wild-rye (Elymus sibiricus). The long, slender, curved awns on untreated seed $(A)$ make it impossible to handle the seed with ordinary machinery, whereas the processed seed $(B)$ is easily planted. 
first milling over a scalper and milling the awned seeds a second time. Both fractions were then combined and cleaned.

Screens with $1 / 4$-inch round perforations were satisfactory for milling all grasses except tall oatgrass, which required a $3 / 16$-inch screen. In general, the correct size of hammer-mill screen was found to be one in which the diameter of the perforation was slightly greater than the length of the caryopsis.

\section{INJURY TO SEED}

The injury to grass seed caused by milling can be held to less than 3 percent except with bulbous barley and squirreltail, for which it increases to approximately 15 and 20 percent, respectively. The values for injury in milling are obtained by subtracting the percentage injured in the check from the percentage of processed seed that was injured (table 3). Bulbous barley seed is large and brittle. It has a narrow, pointed embryo at the proximal end, and the lemma with its long, stiff awn is characteristically fused to the caryopsis. Some of these features are seen in figure $3, A$. The seed of squirreltail is slender, fragile, and tapered at both the proximal and distal ends. The lemma is fused to the caryopsis and terminates in a long tapered awn. It is obvious that milling, even when carefully done, will cause damage to these seeds.

\section{LOSS IN WEIGHT}

Loss in weight was chiefly a loss of inert matter except in bulbous barley and squirreltail, for which a small percentage of the loss can be attributed to ground seed. Part of the loss in weight of bluebunch wheatgrass, tall oatgrass, and squirreltail was in the chaff and straw that could not be removed by cleaning awned seed but was easily separated from milled seed. This is reflected in the percentage of purity. If the purity of any seed was increased 10 percent or more by processing, as it was for these three grasses, the untreated sample contained a considerable amount of inert matter. The amount of straw, chaff, and sterile glumes was especially high in squirretail, and purity was increased from 41.0 percent to 92.9 percent, or more than 50 percent. The loss in the weight of bulbous barley, 55.0 percent, was to be expected because of the relatively high proportion of awns, sterile glumes, and persistent rachilla segments in the untreated sample. The proportion of awns to seed was also high in Canada wildrye and squirreltail. These relationships are reflected in the determinations of seeds per pound, high values for percentage loss in weight correlating with high values for percentage increase in seeds per pound, when proper deductions are made for changes in purity due to the removal of inert matter. Essentially, therefore, a loss in weight incurred by processing grass seed is indicative of a loss of inert matter, the removal of which makes a superior product. In fact, milling actually facilitated the cleaning operation.

It has been pointed out that seed of one accession of each species was used throughout these studies. This was done because it was found that there was some variation between lots, which might have affected the outcome of the tests. An example of the variation between lots was obtained by processing four accessions of blue wild-rye. 
The values for loss in weight were $6.75,7,9$, and 10 percent. For three lots of Siberian wild-rye, losses in weight were 9, 10, and 14 percent. Sufficient allowance for variation between lots should therefore be made when the results of any test are put to practical use. It is recommended that preliminary trials with no less than 30 pounds of seed and 3 minutes of full operation be made with each lot of seed when a high degree of efficiency or accuracy is desired. Although these values are for loss in weight, values for other criteria of the results of processing would also show similar variation between lots.

\section{LIVE PURE SEED}

Processing increased the percentage of live pure seed in five of the seven grasses and decreased it slightly in Siberian wild-rye and bulbous barley (table 3). The decrease in Siberian wild-rye was within the limits of experimental error. The values for percentage purity and germination are the components of the values representing changes in quality as expressed by the percentages of live seed. The large increases in live pure seed obtained by processing bluebunch wheatgrass, tall oatgrass, and squirreltail, the original samples of which contained considerable inert matter, are due chiefly to the increase in the purity of the seed, made possible by the fact that milling facilitated cleaning. The germination of bluebunch wheatgrass was increased, because milling removed nonviable shriveled seed. Reduction of germination in bulbous barley and squirreltail is correlated with injury, which could not be avoided; nevertheless, the quality was sufficiently increased to compensate for the loss from injury.

\section{TEST WEIGHT}

Another important advantage of processing is the increase in test weight per bushel. In table 3 the values are expressed in terms of a factor that indicates the numerical increase. The reciprocal of this factor indicates the volume of the final product in relation to the original. For example, the volume of processed Canada wild-rye is approximately one-fifth that of the untreated seed. The advantages of this reduction to storage and handling are immediately apparent and are of commercial value.

\section{Costs}

Costs for processing grass seed ranged from 67 cents to $\$ 1.50$ per hundred pounds, the lower figure being for blue wild-rye and the higher for bulbous barley. The cost of milling alone was 20 and 80 cents per hundred pounds, respectively, for the same species. Since cleaning is essential, even if the seed is not deawned, this part of the operation might have been deducted, but it was included in the costs shown in table 3 because the cleaning operation is influenced by milling. Costs for milling and cleaning are not shown separately in table 3 . It should also be pointed out that since the costs are based on relatively small lots they may be somewhat high. 
Data arailable for processing one 5,588-pound lot of tall oatgrass show the cost was 85 cents per hundred pounds, which corresponds closely with the cost of processing reported for this species in table 3. It should be pointed out again that these costs are based on direct charges only and on the weights of the original seed, with a reasonable prorated addition for supervision; hence their essential value lies in their use in direct comparisons between species. Nevertheless, the cost of processing is low, especially when considered in relation to the improvement in quality and the greater ease in planting.

\section{DEAWNING OTHER SEEDS}

The processing of alfileria and virgins-bower seed was easily and successfully accomplished, and the processed seed was much superior to the untreated seed (table 3). Injury was low, loss in weight was almost entirely in inert matter, and purity was markedly increased. More important still was the resultant increase in germination, due to the scarification accomplished by the milling. Increases of 38.10 and 27.88 in the percentage of live pure seed of alfileria and virginsbower, respectively, with 98 and 100 percent of the seed deawned,

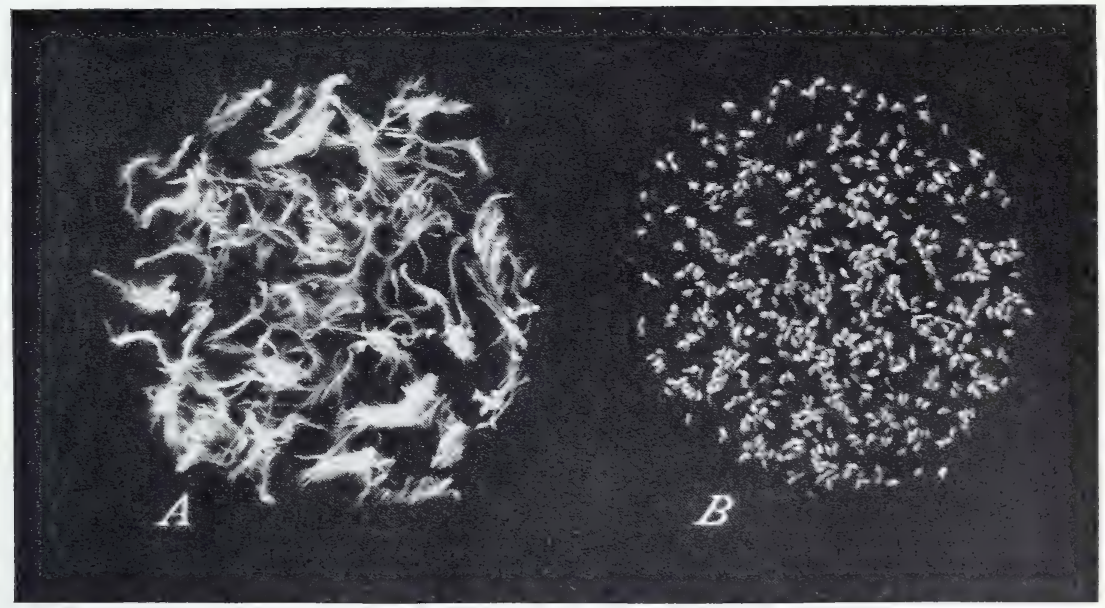

Figure 7.-Seed of virgins-bower (Clematis ligusticifolia) before $(A)$ and after $(B)$ it was processed to remove the persistent styles.

greatly facilitated the handling of these seeds in the field and in the nursery. Had increases in the number of seeds per pound and the weight per bushel been determined, they undoubtedly would have equalled or exceeded the corresponding increases in the grass species. The effect of processing seed of virgins-bower can be seen in figure 7 . The cost of processing the seed of alfileria and virgins-bower was $\$ 1.18$ and 92 cents per hundred pounds, respectively. These costs are within the limits obtained for grass seed and are justified by the improvement in the seed. 


\section{RELATION OF OPTIMUM MILL SPEED TO DIAMETER. OF CYLINDER}

The comparison was made of two medium-sized hammer mills in processing the seed of blue wild-rye and tall oatgrass. The specifications for these mills are given in table 1. One has swinging hammers, the other solid hammers. Preliminary trials were made to determine optimum cylinder speed for each mill, and then trials at not less than 100 r. p. m. above and below the optimum speeds were made. The detailed data are not presented, but when optimum speeds were used with correct screen size, the mills showed no essential difference. It was found that the optimum speed of the 22-inch cylinder was 940 r. p. m. for blue wild-rye and 900 r. p. m. for tall oatgrass, whereas, the corresponding speeds with the 26 -inch cylinder were 730 and 720 r. p. m., respectively. In other words, the small cylinder was used at approximately 25 percent greater speed than the larger cylinder. It therefore appears that the periphery speed of the cylinder in feet per minute determines the effectiveness of the operation. The circumference of the 22-inch cylinder was 5.759 feet; that of the 26 -inch cylinder was 6.807 feet or 18 percent greater. The periphery speed of the smaller cylinder at 940 r.p. m. was 5,413 feet per minute and that of the larger cylinder at 730 r. p. m. was 4,969 feet, a difference of only 8.9 percent in favor of the smaller cylinder. This difference could, no doubt, be reduced, since the variation of $\pm 25 \mathrm{r}$. p. m. must be allowed when determining optimum cylinder speed.

The presumption is that for medium-sized mills, other conditions being equal the speed of operation should vary from the optima recommended in table 3 by about $40 \mathrm{r}$. p. m. for each inch of difference in diameter of the cylinder, being decreased with increases in diameter, and vice versa.

It should be noted that the area of screen was 68 square inches greater in the 26-inch mill, the effect of which was not determined. This mill also had 364 square inches of a $y_{2}^{\prime}$-inch screen spot-welded in the hood, which may have been effective in the work. However, the data are taken to indicate that these differences are less significant than the periphery speed of the cylinder.

\section{SUMMARY}

This circular reports methods of processing seed to remove awns and other appendages from species that have been restricted in their use because of the difficulty of planting them with ordinary machinery. Seed of the following species adapted to the Pacific Northwest were processed: Bluebunch wheatgrass (Agropyron spicatum), blue wild-rye (Elymus glaucus), Canada wild-rye (E. canadensis), Siberian wild-rye (E. sibiricus), tall oatgrass (Arrhenatherum elatius), bulbous barley (Hordeum bulbosum), squirreltail (Sitanion hystrix), alfileria (Erodium cicutarium) and virgins-bower (Clematis ligusticifolia).

Processing was done by milling threshed seed in a hammer mill and cleaning it with a seed cleaner.

Seed can be successfully milled if the speed of the hammer-mill cylinder is reduced to less than half the normal grinding speed, the correct size of screen used, and the mill fed at the full rate. 
The speed of the hammer-mill cylinder required to obtain the optimum condition of seed can be determined for each kind and lot of seed within $50 \mathrm{r}$. p. m. The seed used in these studies required speeds between 600 and nearly 1,200 r. p. m. Cylinder speeds greater than the determined optima increase the percentage of injured seed and decrease the effectiveness of deawning.

A hammer-mill screen of correct size is one in which the diameter of the perforations is slightly greater than the length of the seed or kernel.

Seed must be fed into the hammer mill at about the full capacity of the machine at the determined speed. Feeding at approximately half capacity increases the percentage of injured seed and decreases the percentage of deawned seed.

The percentage of seed injured by milling can be held very low by attention to speed, screen size, and feeding. The structure of the seed of a few species, however, is such that any mechanical treatment will cause damage. Among these are bulbous barley and squirreltail, in which the proportion of injured seed was approximately 15 and 20 percent, respectively.

Processing seed by the method described reduced the weight, the percentage of loss in weight depending on the species and the purity of the sample before treatment. Loss in weight in all seeds is largely compensated by increases in the percentage of live pure seed or the number of seeds per pound, or both.

Processing seed greatly reduces its bulk, the volume of treated grass seed being between approximately one-half and one-eighth that of the untreated sample, as measured by changes in test weight per bushel. This reduction in bulk facilitates both handling and storage.

The two types of hammer mill compared in these studies proved equally effective at the optimum speed for each machine. The data indicate that, for medium-sized mills, the periphery speed of the cylinder determines the correct operation and show that for machines having cylinders of different diameters the speed of the cylinder varies inversely about 40 r. p. m. for each inch of increase in diameter.

The direct cost of processing is low, ranging between 67 cents and $\$ 1.50$ per hundred pounds of original seed. Both milling and cleaning were included in the cost of processing because milling facilitates the cleaning operation and hence cannot be considered separately. 

WHEN THIS PUBLICATION WAS LAST PRINTED

Secretary of Agriculture.

Under Secretary

Assistant Secretary

Director of Information

Director of Extension Work

Director of Finance.

Director of Personnel

Director of Research

Director of Marketing.

Solicitor.

Land Use Coordinator

Office of Plant and Operations

Office of C. C. C. Activities

Office of Experiment Stations

Office of Foreign Agricultural Relations

Agricultural Adjustment Administration

Bureau of Agricultural Chemistry and Engineering.

Bureau of Agricultural Economics.

Agricultural Marketing Service

Bureau of Animal Industry.

Commodity Credit Corporation.

Commodity Exchange Administration

Bureau of Dairy Industry

Bureau of Entomology and Plant Quarantine

Farm Credit Administration.

Farm Security Administration

Federal Crop Insurance Corporation

Federal Surplus Commodities Corporation

Food and Drug Administration.

Forest Service

Bureau of Home Economics

Library

Division of Marketing and Marketing Agreements.

Bureau of Plant Industry

Rural Electrification Administration

Soil Conservation Service

Weather Bureau
Henry A. Wallace.

Claude R. Wickard.

Grover B. Hill

M. S. Eisenhower.

M. L. WILson.

W. A. JUMP.

Roy F. Hendrickson.

JAMES T. JARDine.

Milo R. Perkins.

Mastin G. White.

M. S. Eisenhower.

Arthur B. Thatcher, Chief.

Fred W. Morrell, Chief.

James T. JARdine, Chief.

Leslie A. Wheeler, Director.

R. M. Evans, Administrator.

Henry G. Knight, Chief.

H. R. Tolley, Chief.

C. W. Kitchen, Chief.

John R. Mohler, Chief.

Carl B. Robbins, President.

J. W. T. Duvel, Chief.

O. E. ReEd, Chief.

Lee A. Strong, Chief.

A. G. Black, Governor.

W. W. Alexander, Administrator.

Leroy K. Smith, Manager.

Milo R. Perkins, President.

Walter G. Campbell, Chief.

Earle H. Clapp, Acting Chief.

Louise Stanley, Chief.

Claribel R. Barnett, Librarian.

Milo R. Perkins, In Charge.

E. C. Auchter, Chief.

Harry Slattery, Administrator.

H. H. Bennett, Chief.

Francis W. Reichelderfer, Chief.

This circular is a contribution from

Soil Conservation Service

Office of Technical Operations

Nursery Division
H. H. Bennett, Chief.

C. B. Manifold, Asst. Chief of Service in Charge.

F. J. Crider, Acting Chief. 16

U. S. GOVERNMENT PRINTING OFFICE: 1940 

